TOWSON UNIVERSITY

OFFICE OF GRADUATE STUDIES

TRANSGENDER MICROAGGRESSIONS IN THE CONTEXT OF ROMANTIC

RELATIONSHIPS

\author{
by \\ Lex Pulice-Farrow \\ A thesis \\ Presented to the faculty of \\ Towson University \\ In partial fulfillment for the degree \\ Master of Arts \\ Department of Clinical Psychology
}

Towson University

Towson, Maryland, 21252

May, 2017 


\section{TRANSGENDER MICROAGGRESSIONS}

\section{Acknowledgements}

First and foremost, my deepest gratitude to Dr. Paz Galupo, for guiding me through this process, for your seemingly-never-ending patience and support, and for the opportunities allowed to me through your mentorship. Thank you to my committee, Dr. Christa Schmidt and Dr. Matt Mychailyszyn, for your time and support of my studies. Thank you to my participants, for allowing your voices to be heard and stories to be told through this research - I am honored to be able to share your words. Thank you to my family for their never-ending support and encouragement, and to my lab partner Johanna Ramirez, for her unparalleled insight into my research. Finally, thank you to my partner, Halden. This wouldn't have been possible without you. 


\section{TRANSGENDER MICROAGGRESSIONS}

Thesis and Dissertation Guidelines | 30

\section{TOWSON UNIVERSITY}

OFFICE OF GRADUATE STUDIES

THESIS APPROVAL PAGE

This is to certify that the thesis prepared by [INSERT Student's Name]

Lex Pulice-Farrow

Transgender Microaggressions in the Context

of Romantic Relationships

has been approved by the thesis committee as satisfactorily completing the thesis
requirements for the degree_[INSERT Type of Degree] Master of Arts
(for example, Master of Science)




\title{
TRANSGENDER MICROAGGRESSIONS
}

\begin{abstract}
Microaggressions can shape the everyday experiences of individuals who identify as transgender, and how they approach their relationships. Microaggressions involve subtle forms of discrimination that can come across as environmental, behavioral, or verbal slights. The present study focuses on transgender microaggressions that occur in the context of romantic relationships. Participants included 343 adults who identified as transgender, transsexual, gender non-conforming, and/or having a transgender history. These participants were either currently in a romantic relationship, or had been in a romantic relationship within the last five years. Participants completed an online survey and provided information regarding their experiences of microaggressions from their romantic partners. Responses were analyzed via thematic analysis resulting in four relationship-salient themes: 1) questioning identity; 2) gendered expectations; 3) public negotiation of transgender identity and relationship; and 4) relationship dynamics. Discussion focuses on understanding how microaggressions are shaped by expectations of the gender binary and how they serve to reinforce power differences in romantic relationships of transgender individuals.
\end{abstract}

Keywords: transgender, microaggressions, romantic relationships, gender identity 


\section{TRANSGENDER MICROAGGRESSIONS}

\section{Table of Contents}

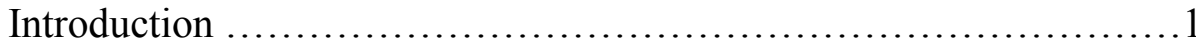

Transgender Experience of Discrimination....................

Microaggressions in the Transgender Community..............2

Transgender Romantic Relationships........................4

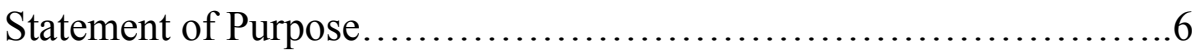

Method.................................................................

Participants.................................................

Measures..................................................... 8

Qualitative Responses: Open-Ended Questions................8

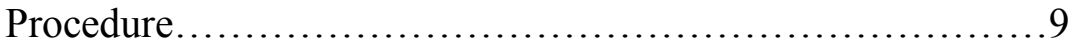

Data Analysis......................................... 9

Results and Discussion ....................................... 10

Themes of Microaggressions..................................11

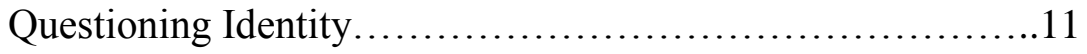

Gendered Expectations......................................14

Public Negotiation of Transgender Identity and Relationship..16

Relationship Dynamics...................................18

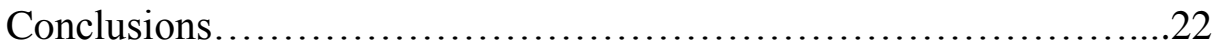

Transgender Microaggressions in Romantic Relationships:

Pervasiveness of Gender Binary.......................23

Transgender Microaggressions in Romantic Relationships:

Power and Negotiation of Transgender Identity.........25

Strengths and Limitations....................................26 


\section{TRANSGENDER MICROAGGRESSIONS}

Future Directions.........................................28

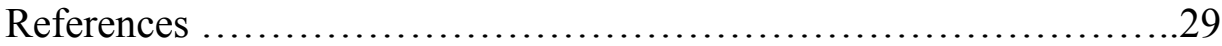

Appendix A: IRB Approval Form..................................40

Appendix B: Online Survey....................................41

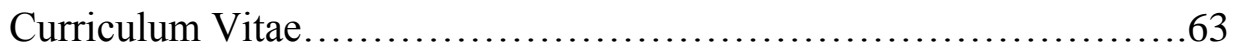




\section{TRANSGENDER MICROAGGRESSIONS}

List of Tables

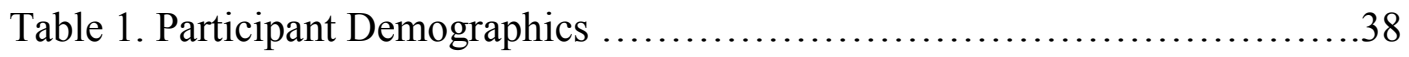

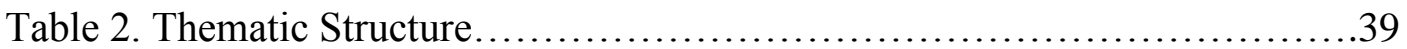


TRANSGENDER MICROAGGRESSION

Transgender Microaggressions in the Context of Romantic Relationships

The present study is among the first to consider microaggressions that

transgender ${ }^{1}$ individuals experience within the context of their $^{2}$ romantic relationships.

While research on transgender microaggressions has increased in recent years, it has most often been studied from within the larger framework of the lesbian, gay, bisexual, and transgender (LGBT) community. Previous research has shown that transgender microaggressions are dependent on context and temporality (Nadal, Skolnik, \& Wong, 2012). Microaggressions are also sensitive to identity differences within social relationships, and have been studied in friendships (Galupo, Henise, \& Davis, 2014), workplace relationships (Galupo \& Resnick, 2016), and in school (Francis \& Reygan, 2016; Ylioja, Cochran, Woodford, \& Renn, 2016) and counseling contexts (Whitman \& Han, 2016). The present study extends this work and utilizes a qualitative approach to examine the nature and impact of transgender microaggressions that are experienced within romantic relationships.

\section{Transgender Experiences of Discrimination}

Gender identity is commonly thought of as an individual's inherent sense of their own gender and how they relate to being female, male, both, or neither (Tate, Youssef, \& Bettergarcia, 2014). Typically, gender/ $\mathrm{sex}^{3}$ is socially constructed as dichotomous, and is one of the most pervasive psychological constructs in today's society (Egan \& Perry, 2001).

\footnotetext{
${ }^{1}$ Consistent with past transgender research (Beemyn \& Rankin, 2011) this study will use transgender as an all-encompassing term used to refer to people whose gender identity does not match their assigned sex at birth.

${ }^{2}$ The singular they pronoun in place of his or hers is also used to acknowledge non-binary identities that are expected within our sample, and the use of pronouns that do not endorse the gender binary.

${ }^{3}$ Following van Anders (2015), we use gender/sex to reference a concept that cannot be understood as only biologically or socially constructed.
} 
TRANSGENDER MICROAGGRESSION

The term transgender typically refers to a person whose gender identity does not match with their sex assigned at birth, or with the societal expectations for a male or female gender expression (Bilodeau \& Renn, 2005). Cisgender individuals, on the other hand, are those who closely identify with the sex they were assigned at birth (Tate et al., 2014). Much of the discrimination that transgender individuals must combat is rooted in cisgenderism, the ideology that assumes that an individual's gender identity matches their sex assigned at birth (Blumer, Ansara, \& Watson, 2013).

Having a transgender identity puts individuals at risk for discrimination and violence. Anti-transgender prejudice, or the verbal, physical, or structural maltreatment of transgender individuals, is prevalent in most parts of life for transgender people (McCullough, 2016). Transgender individuals are more likely to receive verbal and physical harassment than their cisgender counterparts (James et al., 2016). In schools, nearly half of transgender youth are physically or verbally harassed due to their gender and gender presentation, while on the street, nearly $60 \%$ of individuals are mistreated by law enforcement (James et al., 2016). Transgender people are also more likely to be homeless, more likely to experience discriminatory treatment at their place of worship, and are more likely to participate in sex work (Testa et al., 2012).

Even familial and intimate relationships are not safe havens. According to the National Transgender Discrimination Survey, while the vast majority of transgender individuals $(82 \%)$ noted at least one member of their immediate family had supported them in some way, $46 \%$ of transgender individuals had also experienced rejection from a family member based on their identities (James et al., 2016). In addition, more than half of the individuals surveyed reported experiencing intimate partner violence by a current or former partner (James et al., 2016). Forty-four percent of individuals surveyed also 
TRANSGENDER MICROAGGRESSION

acknowledged their partners attempting to coerce, control, or manipulate them by using their transgender status. This discrimination from partners can lead both to an increase in illicit substance use (Reisner, Gamarel, Nemoto, \& Operario, 2014) as well as to negative mental health outcomes (Meier, Sharp, Michonski, Babcock, \& Fitzgerald, 2013).

\section{Microaggressions and the Transgender Community}

While much of the discrimination that transgender people face is systematic and overt, some instances are more covert. Microaggressions are environmental, verbal, or behavioral indignities that can occur briefly or routinely, and serve to communicate negative or derogatory snubs toward minority communities (Sue, 2010). There are three types of microaggressions, all of which negatively affect the mental and physical health, well-being, and standard of living of marginalized groups and minority individuals. Microassaults are the most detrimental, and are overt, deliberate acts that are meant to intimidate or harm minority groups, whereas microinvalidations and microinsults are unconscious, usually covert behavioral or verbal slights that question the experienced reality of the individuals they target (Sue, 2010). Much of what is currently known about transgender microaggressions has been previously framed within the context of the LGBT community. While some results can be drawn from this community at large, it is important to keep in mind the conflation of the experiences of sexual and gender minorities cannot lead to all-encompassing generalizations, as the variance between sexual and gender minorities is sizeable (Valdes, 2013).

Nadal and colleagues $(2012 ; 2014)$ were the first to focus exclusively on transgender microaggressions. In their study, themes were described that portrayed transgender-specific microaggressions, including language-, body-, and environmentallybased microaggressions (Nadal et al., 2014). Though all individuals who experience 
TRANSGENDER MICROAGGRESSION

microaggressions routinely feel distress, transgender individuals are more likely to report feelings of betrayal, exhaustion, or hopelessness than their cisgender counterparts after routinely experiencing microaggressions from loved ones (Nadal et al., 2014). Constant assumptions and expectations about an individual's gender and body can cause transgender individuals to negatively ruminate on their gender or presentation, and the more assumptions that are made regarding an individual's body, the more negative mental health outcomes they experience (Smith, Shin, \& Officer, 2012). Transgender individuals also report heightened levels of vigilance in order to ensure physical safety after receiving a microaggression (Nadal et al., 2014).

Previous research has shown that transgender microaggressions are specific to both the perpetrator and the context with which they are received (Nadal et al., 2014). Microaggressions have been shown to impact the social support systems of transgender individuals, and are experienced frequently in close friendships (Galupo, Henise, \& Davis, 2014). The experience of microaggressions differs across both the gender identity (cisgender vs. transgender) and sexual orientation (sexual minority vs. heterosexual) of the friend (Galupo, Henise, \& Davis, 2014), as well as the gender identity of the individual (Pulice-Farrow, Clements, \& Galupo, Under Review). In addition, transgender microaggressions occurring within a friendship impact the closeness and trust felt toward the friend, leading to a disruption of social support (Galupo, Henise, \& Davis, 2014). This research serves as a model for studying microaggressions in close relationships and could be usefully applied to understanding romantic relationship experiences of transgender individuals.

\section{Transgender Romantic Relationships}

Research on transgender romantic relationships is relatively limited, and focuses 
on transgender women and transgender men to the exclusion of individuals who endorse non-binary identities (Brown, 2010; Velez, Breslow, Brewster, Cox, \& Foster, 2016). However, from what we do know about these romantic relationships, they are incredibly important to the mental health and well-being of transgender individuals. Transgender individuals in relationships report lower levels of depression than individuals who are single (Meier et al., 2013). Transgender individuals are also more likely to report higher levels of identity affirmation from intimate partners than from family members (Nuttbrock et al., 2009).

Transgender individuals have sexual orientations that are just as diverse as their cisgender counterparts, and can identify as heterosexual, lesbian, gay, bisexual, or asexual. The shifting of sexuality following an individual medically/socially transitioning genders has been noted in many studies (Bockting, Benner, \& Coleman, 2009; Davis \& Meier, 2014; Galupo, Henise, \& Mercer, 2016; Meier et al., 2013). While some relationships can (and do) endure and thrive within the context of gender transition, this transition may also signal the end of a romantic relationship, due to partners facing a certain level of grief when suddenly being faced with a differently gendered partner and a reframing of their own sexual identity (Meier et al., 2013). The process of gender transition may also lead to large shifts in partner roles within an intimate relationship (Meier et al., 2013). However, individual variation exists within these relationships. Some partners may handle a change in partner's gender (and the potential change to their sexual identity) very well, while others may feel it an irreconcilable disconnect and choose to terminate the relationship (Hines, 2009). Many transgender people find it hard to initiate a new relationship following transition, for fear of rejection, body dysphoria, or lack of the individual's body acceptance (Hines, 2009). However, it should be noted that 
research currently does not know all of the factors that affect the partnerships of transgender individuals (Brown, 2010).

The romantic relationships of transgender individuals are unique - both to the individuals involved in them and the challenges they may face. Previous studies that have examined microaggressions in romantic relationships have focused on inter-racial/ethnic couples (Jones, 2011) and in couples of different sexualities (Flanders, Robinson, Legge, \& Tarasoff, 2015). These studies have acknowledged that romantic partners may not fully understand the experience of someone with a different social identity, which may lead to the perpetuation of microaggressions (Flanders et al., 2015; Jones, 2011). Since microaggressions are specific to time and to context (Jones, 2011), and transgender microaggressions have been studied in many different settings (Galupo, Henise, \& Davis, 2014; Galupo \& Resnick, 2016), it follows that these microaggressions may take different form and meaning when experienced in romantic relationships as well. To date, there have been no studies that focus on the microaggressions that transgender individuals receive from their romantic partners.

\section{Statement of Purpose}

There is currently little to no information on the dynamics of transgender relationships (Davis \& Meier, 2014; Meier et al., 2014), or of the microaggressions perpetuated within them. Since microaggressions are sensitive to time and context, it follows that transgender microaggressions should be studied within different social environments. The proposed study focuses on microaggressions as a model for understanding the relationship dynamics of transgender individuals.

The present study utilized a sample of transgender-identified individuals, and focused directly on their romantic relationships. It takes a qualitative approach in order to 
TRANSGENDER MICROAGGRESSION

obtain and explore a full scope of microaggressions that transgender individuals

experience from their romantic partners. Participants were asked to provide examples of microaggressions experienced from within their own romantic relationships. They were also asked to describe their feelings about the microaggression and the impact it had on the romantic relationship. The present analysis focuses on addressing the following research question: What themes of transgender microaggressions emerge from within the context of a romantic relationship?

\section{Method}

\section{Participants}

Participants included 343 adult individuals who identified as transgender, transsexual, gender non-conforming, and/or having a transgender history. Participants first provided their gender identity as a write-in response, and were then asked to choose which of the four categories they most identify with: transfeminine $(n=40)$, transmasculine $(n=101)$, gender non-conforming $(n=123)$, or agender $(n=99)$. To participate, the participants had to currently be in or have formerly been in a romantic relationship. If the participants choose to reference a previous relationship, it must have taken place within the last five years, and while the participant identified as transgender. Participants ranged in age from 18 to $100,(M=23.33, S D=7.65)$. The majority $(76 \%)$ of participants were US residents, and the sample represents 46 states, Washington DC, and 19 countries. Table 1 includes participant demographics with regard to racial/ethnic diversity, highest level of education, and socio-economic status. There was limited racial/ethnic diversity in the sample, with $81.2 \%$ identifying as White/Caucasian and $18.8 \%$ identifying as a racial or ethnic minority. Thirty percent of our sample identified as working class, while $38 \%$ of the sample identified as having taken at least some 
college courses.

Recruitment announcements, including a link to the online survey, were posted to social media sites, online message boards, and emailed via transgender listservs. Some of these resources were geared toward specific sexual minority communities, while others served the transgender community more generally. Participants heard about the study primarily through online means, including Tumblr (85.1\%), Facebook (12.1\%), and receiving a forwarded email from an acquaintance or listserv (2.2\%). Two participants acquired access to this survey through different venues.

\section{Measures}

As part of a larger dataset on positive and negative experiences of romantic relationship for transgender individuals, participants took an online survey, where they answered questions regarding their experiences of romantic relationships. The present analysis focuses on questions relating to microaggressions experienced within romantic relationships.

\section{Qualitative Questions: Open-Ended Responses}

Three open-ended prompts were analyzed that detailed microaggressions experienced within the context of a romantic relationship. The prompts were designed to target the three main categories of microaggressions (microassaults, microinsults, and microinvalidations) as outlined by Sue (2010). For clarity, participants were provided an example of each, and were then asked to provide an instance from their romantic relationships (i.e., "Provide an example from your romantic partner in which these actions have been directed toward you due to your gender identity. Please describe the experience in detail and include both your internal (emotional) reaction as well as any feedback or action you made to the situation"). 


\section{Procedure}

Data from all three prompts were considered together for thematic analysis. Participants completed an online survey that sought to explore themes of transgender microaggressions that may be present in romantic relationships. Participants first completed demographic questions, including structured gender identity question was presented to participants where they chose their primary gender identity from discrete options: transfeminine, transmasculine, gender non-conforming, and agender. Participants were then invited to expand and give a more detailed conceptualization of their gender identity as they experienced it. All participants were then asked to discuss their personal experience of microaggressions (Sue, 2010) in relation to their romantic relationships.

\section{Data Analysis}

Thematic analysis (Braun \& Clark, 2006) was used to consider how participants described their experiences of microaggressions that were perpetuated within the context of their romantic relationships. Analysis began with members of the research team independently coding data looking for themes related to types of microaggressions found in romantic relationships. The research team met and discussed the coding categories and agreed upon an initial set of codes. Four main themes were agreed upon, with subcategories of each theme. Two members of the research team then coded and sorted the data set using the initial set of sorted codes quotes based on theme, while the faculty member served as an external auditor. The entire research team agreed upon the coding structure and met several additional times to discuss and solidify which quotes would fit under each theme. Final quotes were chosen to simultaneously exemplify each theme and to ensure that the quotes best represented the diversity of experiences based on the gender 
identity endorsed by the sample.

Several checks were included in our data analysis process in order to increase the credibility of our results. First, at the end of the survey we provided participants with the opportunity to reflect upon how our questions captured (and failed to capture) their individual experiences. Participants were also asked to provide feedback to improve the present and future studies. Some responses obtained were incorporated into the analysis, as participants' clarified demographic information. Second, throughout the data analysis process we discussed the themes and made decisions via consensus. Because of the range of our collective experiences across gender identity, gender presentation, sexual orientation, relationship experiences, race, and religion, we came to these discussions with different perspectives. Our research team included a second-year clinical psychology graduate student who identifies as a queer genderfluid person, an undergraduate psychology student who identifies as a transgender woman, and a Professor of Psychology who identifies as a bisexual/pansexual cisgender woman and whose spouse is gender non-conforming/non-binary.

\section{Results and Discussion}

Participants provided self-generated data about the microaggressions they have experienced within romantic partnerships, the circumstances surrounding these microaggressions, and their response(s) to them. Prior to describing the findings, it is important to note that participants were asked to choose one relationship (past or present) to use across the entire survey. As an artifact of these instructions, some participants chose a present relationship when initially asked, but referred to past relationships during their responses. For example, when asked to provide an example from a current partner, one participant indicated, "Nothing from [my] current partner, but plenty from previous 
partners." Although our analysis focused on the nature and context of microaggressions when they occurred, many participants took the opportunity to describe that their current partner did not perpetuate microaggressions, such as: "My partner has never done actions, intentionally or otherwise that fit what is described above." Some participants may have qualified these statements with their partner's identity, indicating: “Due to my partner's own gender identity, he is very aware of this kind of behaviour and has not attempted to do anything related to this." Other participants registered a sense of shock at the apparent presumption that their partner would do something like this. When asked about their experience of microaggressions, one participant stated: "Not all trans and queer relationships are violent?? This has also never happened to me."

\section{Themes of Microaggressions}

Thematic analysis revealed four relationship-salient themes: 1) questioning identity; 2) gendered expectations; 3) public negotiation of transgender identity and relationship; and 4) relationship dynamics. Table 2 summarizes the thematic structure. Results are described using direct quotations from participants, accompanied by their self-identified gender label(s) and age. All participants are represented within the thematic structure. The participants often exemplified multiple themes/subthemes, as the themes are not mutually exclusive.

\section{Questioning Identity}

Participants described transgender microaggressions from their romantic partners that centered on questioning identity. Two subthemes were identified within this category: 1) participant's transgender identity; and 2) partner's identity. In some cases, it was the participant's identity in question. In others, the microaggression came from the partner's assumption about how the participant's transgender identity reflected on their 
own identities.

Within this theme, many participants described microaggressions that challenged or ignored their transgender identity.

When I first came out, he tried relentlessly to convince me that I was not trans. He made it very clear that he did not "believe" in non-binary genders. I was, predictably, very upset and disappointed. He eventually came around, but it's clear he still thinks of me as female. (Agender, 23)

When we had just started dating and I was only starting to figure out my gender identity (and they identified as solely female), they told me they saw me as not really having a gender. I just wanted, as a lot of trans people seem to want, somebody to validate me as male before I said it out loud myself. (Transguy, 20) These microaggressions functioned to question the authenticity of the person's transgender identity. Authenticity for transgender individuals can be conceptualized as the personal navigation of an identity, label, or presentation that feels congruent with their unique gender conceptualization (Boskey, 2014). Other participants noted that their partners would make comments that were dismissive of their identity. These could have been based on having a pre-conceived notion of how the participant's gender identity should factor into their gender expression.

Implying that since I'm something like a trans guy I couldn't possibly be interested in "non-masculine" activities (even when there is obvious evidence that I do). And making comments about how "transmasculine people are" while eye rolling.

(Trans-man [ish]/genderless, 29) 
TRANSGENDER MICROAGGRESSION

Participants described other microaggressions that centered on their partner's identity, whether this was their gender or sexual identity. This type of microaggression expressed differently by transgender and by cisgender partners. From partners who also identified as trans, there was an assumption of shared experience, whether or not the partners shared a similar gender identity.

One of my previous partners, a trans boy, made me feel invalidated about my gender identity (unintentionally) as a non-binary person. He complained about his experience as a binary trans boy, insisted about gender dysphoria as a necessary factor in gender identity and generally ignored my own struggles with gender identity. This caused me severe anxiety about my own thoughts about my gender and I thought I was doing it wrong and that I was a fraud. (Bigender, 18) However, if the romantic partner identified as cisgender, these microaggressions manifested more as a way to reassure themselves of their own identities.

When he's feeling insecure about his orientation and masculinity, he becomes significantly more insistent about calling me a "lady" even when the comparisons he makes are that my behavior is different from all the women he's met and that he likes that I act like a dude. It's really transparent, so it's more annoying than hurtful. (Dude, 26)

Other microaggressions focusing on the partner's identity centered around sexual orientation. An individual's transition may mean a new negotiation of a partner's sexual identity, where partners often experience feelings of frustration and confusion (JoslinRoher \& Wheeler, 2009).

At one point, she made comments that insinuated that I was only sexually attracted to her when I was in my female gender. This made me feel very 
TRANSGENDER MICROAGGRESSION

invalidated and unattractive, and like she had to mentally "cast" me as female to have sex with me. It made me feel like I needed to lie to her about my gender in order to be seen as appealing. (Genderfluid, 21)

Many of these responses focused on the participant's genitals, or the partner's unwillingness to let go of a specific sexual orientation label, regardless of whether or not it fit their current romantic relationship. Microaggressions that come from close relationships, such as from intimate partners, may be seen as more harmful from those that come from strangers (Chang \& Chung, 2015) due to the fact that the individual may believe that this person "should have known better" (Galupo, Henise, \& Davis, 2014, p. 465).

\section{Gendered Expectations}

The second theme of microaggressions revolved around the partner's gendered expectations of the participant. Two subthemes were found within this theme: 1) gendering body and intimacy; and 2) gendered preferences and roles.

Microaggressions that centered on gendering of the body, as well as intimate acts, were prevalent within this sample. These types of microaggressions typically left the participant feeling "dysphoric", "deeply uncomfortable," "demeaned," and less confident as a sexual partner.

I'm medically transitioned but decided not to take bottom surgery. Comments that remind me that he likes cis men best, or likes dick best, can be upsetting. Like saying "if only you had a dick it would be easier..." Also, him being obviously unwilling to go down [on me] and making it clear that he's put off by it.

([Transsexual] Man, 24)

These microaggressions also involved invasive questions regarding body parts and 
medical interventions. As one participant noted: "He questioned me about how my vulva was made. I told him it was made using magic."

Other microaggressions showed that the participant's partner had pre-conceived expectations about the ways the participant's gender would affect the relationship. Sometimes, the partner would display a preference for one gender presentation over another. Since only one-half of transgender individuals socially transition, and only onequarter medically transition (Schiem \& Bauer, 2015), having a fluctuating gender presentation may be congruent for individuals who endorse transgender identities. Especially for individuals who endorse gender fluid or non-binary identities, these presentations may fluctuate and shift, with each presentation being just as valid as another (Bornstein, 2013; Galupo, Pulice-Farrow, \& Ramirez, 2017). One participant recognized:

My partner is always more excited when I switch back from male identifying to female identifying. She does try to maintain an equilibrium, but the way she lights up and becomes immediately more comfortable when I identify and present as female feels like it invalidates the times when I identify as male. (Gender Fluid, 25)

Other participants described this microaggression that came from their partner having a stereotypical expectation of their new gender role. This could play into binary notions of masculinity and femininity, as they relate to particular roles, activities, and concepts. One participant described their partner the following way:

Occasional things along the lines of, "but if you're a MAN so you should be able to do it". Made me question my own strength and what it meant to be a man. To this day I still struggle with "am I (stereotypically) manly enough to be considered 
a man?" (Trans male [FtM], 21)

Finally, participants described their partners using inappropriately gendered language, whether it was to speak about the individual to a third party, or to discuss anatomical terminology. This could have also been seen in the language that the partner used with the participant in casual conversation. Some participants were "uncomfortable being seen as just a girlfriend," while others are "uncomfortable being referred to as a woman." This microaggression is further illustrated in the following participant response: My current partner has on occasion called me gendered words like "dude" and has also misgendered me with he pronouns and the name I was using when I was out as a trans boy before I came out as non-binary. It hurts me and makes me feel insecure but they always apologize and correct themself. (Nonbinary, 18)

\section{Public Negotiation of Transgender Identity and Relationship}

Participants described microaggressions from their partner that involved an interaction with people who were outside of the relationship, whether it be friends, family members, or strangers. Within this theme, two subthemes were identified: 1) public vs. private behavior; and 2) not advocating.

Participants described microaggressions that revealed a distinction in the way the partner negotiated their transgender identities when in public versus in private. Participants usually noted a conspicuous difference between how they were treated in the two spheres.

She misgenders me when introducing me to other people, using "she" and "girlfriend" (I rarely to never identify as a woman). I called her out on it and she apologized, reasoning that "it is easier" and "what am I supposed to call us then," although boyfriend is a term I feel much more comfortable with even if I identify 
TRANSGENDER MICROAGGRESSION

as agender at the time. (Genderfluid, 23)

Participants also described microaggressions in which their partner did not advocate for them. This could have been seen in numerous ways: a partner failing to correct others' misuse of pronouns, failing to defend their partner when others made comments that showed anti-transgender prejudice, or refusing to disclose their transgender status to important figures in their lives. For example, one participant described: "When talking about his conversations with others, he refers to me as they see me, with she/her pronouns and as a girl/female."

My [partner] sometimes continues to refer to me in masculine terms, sometimes even by my old name. I'm openly trans and have to play my deadname role in these situations to save face for my partner. (Female, 26)

My partner's father is severely homophobic. Because of this, and the fact that I am pre-hormonal and appear physically female, we have lied to his father and pretended I was female for his sake, because [my partner] still lives with his mother and his father has a history of physically abusing him. Whenever his father is present, everyone refers to me as "she." His father is foreign and doesn't know that my name is a male one. (Trans male, 19)

Participants described microaggressions in this category that directly targeted how they were treated differently in public and private spaces. While they could have been treated with respect privately, being treated differently in public was something that negatively affected participants and caused distress for them. Whether or not the participant acknowledged there being a "reason" for the different treatment, negative feelings were still felt. 
TRANSGENDER MICROAGGRESSION

\section{Relationship Dynamics}

The final theme identified microaggressions that impacted relationship dynamics. These often marked relationship milestones and were related to either relationship and/or the development and negotiation of transgender identity. Within this theme, five subthemes were noted: 1) disclosure; 2) grieving; 3) resistance to transition; 4) fighting; and 5) ending.

Participants described microaggressions occurring at the time of disclosure. As one participant noted,

When I first came out to him, he was horrible to me. He made me promise to keep all my "parts" and insisted he wasn't a fag. He refused to speak with me about my gender, and said since I looked like a girl I must have been a girl. He acted cold and distant towards me, insisting he'd never date one of those "trannys" and that I was ok because it didn't count. (Agender, 21)

If identity disclosure is rebuffed rather than validated, a person may internalize this rejection of their gender identity, which may lead to increased self-stigma (Gamarel et al., 2014). This self-stigma, in turn, could lead to a poorer relationship quality as well as more negative mental health issues for the transgender individual (Bockting, Miner, Swinburne Romine, Hamilton, \& Coleman, 2013).

I was called "disgusting" for coming out and presenting as male. My partner was disgusted by the fact that I stopped shaving and wanted him to call me by my preferred name and pronouns. He kept misgendering me in order to keep identifying as heterosexual. My internal reaction was shock and self-disgust, confusion, and regret. I felt I could not speak up for myself for fear of further abuse. (Non-binary transmasculine, 21) 
Some partners of transgender individuals experience grief when learning of their partner's transgender identity. As Norwood (2012) asserted, these feelings of loss may be profound for some individuals, and typically must be navigated before they can be dealt with constructively. Norwood (2012) showed that the disclosure of an individual's transgender identity might function as a stressor that could be experienced by others as an ambiguous loss. Tensions in the relationship may occur due to these feelings of loss, and some romantic partners may be caught between missing the individual as they were and wanting to support them as they are now (Norwood, 2012). Some individuals may not want to undergo the changes that a partner's gender transition may necessitate, which may cause even more tensions within the relationship. Although this has been understood in the research as an understandable adjustment process for partners, our participants often experienced this as a microaggression.

Shortly after I initially came out to my partner, I had to explain to her my need to actively pursue medical and social transition. Because of this, she expressed "grief over losing her husband" and expressed need to go through that grieving process before she can adjust to and "be happy about her wife." (Woman, 24) Another reaction was the partner's resistance to the participant's transition. These microaggressions may have been in the form of overt statements, or could have been smaller, more covert behaviors that led the participant to feel as though their partner did not want them to socially or medically transition. Some partners were resistant to surgeries that the participant might have. As one participant noted, "I told my partner that I might get top surgery. His response was that I was destroying my body and that it's kind of like committing suicide" (Genderflux, 23). Other partners were resistant to any physical changes by the participant. 
TRANSGENDER MICROAGGRESSION

When I first cut my hair, my partner told me I was ugly and wasn't attractive anymore. it really hurt me but it was also confirmed what I suspected: that she would be opposed to a transition. When I first mentioned going on testosterone she became very upset and did everything in her power to persuade me from going on hormones. I put off my medical transition for her. (Trans non-binary, 26)

My long hair (down to my belt line) was something that my partner really loved about me, but it clashed with how I felt for a long time. We had more than one verbal argument over whether or not I should cut it off. Finally it ended when I said that it was my hair and I would do whatever I wanted, and he had no place to tell me what I could or couldn't do with my body. Internally it was really painful. I felt out of control and afraid that he wouldn't want anything to do with me if I cut my hair. That I would lose my place to live. If cutting my hair was that big of a deal how would I ever be able to actually live as male, as I felt I should? (Transmale, 35)

While seemingly an over-reaction, the above quotation represents the depth to which microaggressions are felt. Most microaggressions are seen as covert instances and are dismissed as a person being "too sensitive" (Sue et al., 2007). However, many minority individuals experience microaggressions from multiple people, multiple times per day (Nadal, 2011). These frequent experiences may lead an individual to feel drained and angry, and may lead to more negative mental health outcomes (Nadal, 2011). Subsequently, if a partner does not support a transgender individual in their transition steps, they may be at risk for homelessness (Edwards-Leeper, Leibowitz, \& Sangganjanavanich, 2016), increased negative mental health outcomes (Meier et al., 
2013), and increased self-stigma (Reisner et al., 2016).

Some participants attempted to deal with their partner's resistance to their transition by trying to maintain the status quo of the current relationship. Typically, the partner would not want certain aspects of their romantic relationship to change following a gender transition. Participants described "attending a formal function and being asked to wear clothes that did not fit [their] gender identity," or how their partners "referred to gender identity as a choice that I could make." Sometimes participants made these concessions out of deference to their partners' comfort, and to their partner's process, given that they transitioned while in the relationship.

He has expressed he is uncomfortable using my trans name and pronouns due to being with me for two years before I transitioned my name and identity (not physically) and not being gay, and asked to use my old name and pronouns. For the sake of our relationship I agreed. Sometimes I feel ok about it, as I do like being girly sometimes, but sometimes I have extreme dysphoria which makes me feel terrible that no one sees me as who I am. (Trans Male, 21)

Other participants described microaggressions from their partners that occurred during fights or arguments during the course of the relationship. Many participants who described these microaggressions typically described them as "only occurring when we fight," or "taking out her anger on me." As one participant further showed:

Generally, she will only use gender (feminine)-specific names when lashing out, i.e. "bitch," "cunt," etc. It's rare that she has episodes such as these, but when she does there is ZERO regard for my position as a non-binary person. In times of stress, she generally reverts to masculine roles (she's mtf) and places me in the position of a "traditional" female. (Non-binary, 21) 
TRANSGENDER MICROAGGRESSION

This is consistent with research that focuses on microaggressions in romantic partners of different racial identities has also identified that microaggressions revolving around these differing identities are more prevalent during arguments or fights had by the couple (Guillen, 2015).

Other microaggressions occurred during times of strife and when a relationship was ending. Some relationships ended due to the participant disclosing their transgender identity, others ended because of the frequency or severity of microaggressions that were experience, and others were dissolved for various other reasons. While some partnerships can (and do) end during an individual's gender transition (Meier et al., 2013), the endurance of romantic relationship through a gender transition has not been adequately studied. Some of the participants acknowledged terminating a relationship My partner didn't really care that I was agender, in a bad way. He told me it was silly to identify as anything other than the gender I was "born with." He broke up with me soon after. I was upset with him for having such a backwards attitude, but I felt like I dodged a bullet when he broke up with me. Someone who doesn't respect me isn't worth my time. (Agender, 22)

Overall, these microaggressions were not only tied to the overall relationship context, but to the relationship's development as well. Microaggressions from a romantic partner changed as the relationship hit certain milestones, highlighting the sensitivity to context as displayed in the literature (Chang \& Chung, 2015; Jones, 2011).

\section{Conclusion}

By considering transgender experiences in romantic relationships, the present findings allow a fuller understanding of the relational impact and consequences of microaggressions. It is important to note, however, that some participants did not report 
microaggressions in their relationships while others mentioned positive aspects of their relationships alongside of microaggressions. While the present study focused exclusively on characterizing microaggressions, these findings do not fully characterize the romantic relationships of transgender individuals.

For our participants, the microaggressions were hurtful not just because of the content of the remark or the intent behind the action, but precisely because of the importance of the relationship. This is supported by previous research findings, which have found that microaggressions that come from close personal relationships (such as friendships and romantic relationships) are seen as more interpersonally aggressive (Chang \& Chung, 2015) and more hurtful (Galupo, Henise, \& Davis, 2014) than if they had come from a stranger or acquaintance.

Previous research has emphasized that although microaggressions are conceptualized as subtle, they are hurtful in part due to their daily occurrence (Sue, 2010). Thus, studies have focused on the frequency of microaggression (Ong, Burrow, Fuller-Rowell, Ja, \& Sue, 2013), as well as their outcome (Huynh, 2012; Wright \& Wegner, 2012). In contrast with this emphasis on accumulated microaggressions, the present findings suggest that sometimes a single microaggression from an intimate partner can have a lasting impact. As one participant noted: "It hasn't happened often, but once or twice my partner has reacted to conversations about my gender identity like it doesn't matter or like he doesn't believe me or doesn't care... I end up repressing my feelings and never talking about them."

Transgender Microaggressions in Romantic Relationships: Pervasiveness of Gender Binary

The present study holds certain implications for the future of how transgender 
microaggressions are studied. A prevalent thread in the way that microaggressions were expressed across all four themes centered on the assumption of a gender binary. The pervasiveness of the gender binary affected all aspects of the relationships, ranging from expectations during sexual intimacy to the experience of gender role behavior within the relationship. These microaggressions affected not only the individuals involved, but how they negotiated their relationship when interacting with the outside world.

Participants found that their romantic partners would place heavily gendered expectations on sexual intimacy and genitalia. For example, one participant described that their partner would "only equate men to people who had penises," while another described that “[during sex], my partner doesn't know how to respond when I call my vagina a penis." This inherently binary assumption of genitals and sexual intimacy caused participants that experienced these microaggressions to feel demeaned and saddened.

Some romantic partners revealed their reliance on the gender binary in their endorsement that participants should fulfill roles and perform behaviors stereotypical of their gender. For example, one participant noted that their partner would say: " 'Men don't cry this much.' Implying if I was a REAL man, not a trans man, I wouldn't get upset over things. "Similarly, other individuals found that their partners would either see them and/or treat them as their sex assigned at birth - in one non-binary participant's words: "I am either read as a man or as a woman - no one ever sees you as truly non-binary."

Participants also noted that their romantic partners would perpetuate gendered expectations on them when negotiating their transgender identity with others. This could have occurred with partners not knowing how to explain the participant's gender to friends or family. While attempting to negotiate a non-normative gender identity with 
others outside of the relationship, participants saw their genders being described in ways that were simplified or incorrect. As one gender non-conforming participant put it: "She 'simplifies' my identity when it's inconvenient for her to explain to others."

The microaggressions our participants received from their partners consistently relied upon rigid assumptions of the gender binary. These assumptions were informed by cisgenderism (Blumer et al., 2013) where partners often defaulted to sex assigned at birth, rather than identity, as the primary lens through which they viewed the participant. Microaggressions were further informed by genderism, where non-conformity of any type was negatively evaluated (Hill \& Willoughby, 2005). Consistent with the literature, non-binary participants were more likely to experience negative evaluations of their gender, based on the fact that they did not endorse a binary gender identity or embrace a stereotypical gender presentation (Tebbe, Moradi, \& Ege, 2014).

\section{Transgender Microaggressions in Romantic Relationships: Power and Negotiation of Transgender Identity}

Romantic relationships are inherently regarded as voluntary and mutual -partnerships into which individuals enter together and willingly (Furman \& Shomaker, 2008). Typically, these relationships are seen as equal, with individuals enjoying a shared, reciprocal exchange of power (Felmlee, 1994). However, cross-category relationships, or ones in which the partners have differing identities, are inherently built around inequality (O’Meara, 1989), where the relationship itself may potentially be maintained at the expense of the partner with the non-normative identity (Galupo, Sailer, $\&$ St. John, 2004). In the case of the present study, microaggressions revealed the way that relationship development and maintenance often took place at the expense of participants' gender identity. 
Participants described their trust in their partners being violated by these microaggressions: “...in the end I left because I knew that she was never a safe partner for me, and that I would never trust her to be no matter how much she or I tried to change." Partners exerted this power by using their normative gender identities to invalidate transgender experience. As one participant noted that their partner would sometimes misgender them, and she 'reasoned that 'it is easier' and 'what am I supposed to call us then,' although boyfriend is a term I feel much more comfortable with." The way that microaggressions were experienced in romantic relationships and were tied to power (Felmlee, 1994) and identity (Nemoto, 2009) is consistent with past relationship research between individuals of different sexual orientations (Flanders et al., 2015) and racial/ethnic identities (Guillén, 2015).

\section{Strengths and Limitations}

The present study yielded interesting results, though it is not without limitations. Our participants represent an online convenience sample, which has proven useful with groups who have a heightened concern for privacy. The Internet may also provide access to support and resources for those individuals who may subsequently be isolated from the transgender community (Riggle, Rostosky, \& Reedy, 2005). However, participants who complete online surveys are disproportionately White, middle class, and educated (Christian, Dillman, \& Smyth, 2008), and this was consistent with our sample demographics. Interpretation of this data must be done cautiously and within the limits of the demographics. Since transgender people of color are more likely to experience microaggressions at the intersection of their racial and gender identities (Balsam, Molina, Beadnell, Simoni, \& Walters, 2011; Nadal, Skolnik, \& Wong, 2012), and our sample was predominately White, our results might be skewed as more positive. 
A second limitation to the study was the wording and order of survey questions, which some participants experienced as offensive. We asked participants to describe both microaggressions and affirming experiences in their romantic relationships (in that order). When asking about microaggressions, participants were asked to detail three types of microaggressions, beginning with the most harmful. The order of the questions led some participant to believe that we were only interested in negative experiences in relationships, or were assuming that all transgender relationships were abusive. As seen in their responses, some participants were frustrated by this, and expressed their frustration in the answer box, as opposed to detailing a microaggression or stating that one did not happen (an answer choice of "N/A"). This may have skewed the data to be more negative and highlight the most hurtful microaggressions. If individuals were angry about being asked about what they considered to be assumed abuse, then they may have not wanted to discuss lesser, more common instances that happened in their everyday lives. Some participants also felt that our language choice asking about "gender identities" instead of "genders" was inherently offensive, as they interpreted this language to imply that cisgender people have "genders" while transgender individuals have "gender identities."

Alternatively, this research displayed strengths as well. The majority of our participants (61.2\%) identified as either gender non-conforming or agender. Non-binary individuals are typically under-represented and understudied in the present microaggression research literature (Nadal et al., 2014). While some studies have begun to include individuals who endorse non-binary genders in their samples (Nadal et al., 2016), this study is among the first to capture the lived experience of non-binary people in romantic relationships, and may help to prompt a new line of research on this 
population. Based on previous literature, there are typically differences seen in the types of microaggressions that individuals who endorse non-binary genders receive (Galupo, Pulice-Farrow, \& Ramirez, 2017), and non-binary people are also more likely to experience discrimination than their binary counterparts (James et al., 2016).

\section{Future Directions}

Though the present research represents a good starting point for examining transgender microaggressions in romantic relationships, future research should direct specific focus on the differences between the microaggressions that individuals who endorse binary and non-binary identities receive in their romantic relationships. In addition, the present study focused on descriptions of microaggressions from the perspective of the transgender individual. Studying the partner's perspective of the microaggressions that they direct intentionally or unintentional within the relationship could be a future area of focus. Examining the partner's experience and understanding of microaggressions could provide a fuller understanding of the negotiation of gender identity in romantic relationships.

Finally, while it is important to understand the negative experiences of transgender individuals in their romantic relationships, it is equally important to examine the positive aspects in these relationships. Most research conducted on transgender individuals and their romantic relationships focuses on the negative aspects and outcomes (Gamarel et al., 2014; Reisner et al., 2014). Efforts should be made to give equal attention to the ways in which partners support and affirm transgender individuals. These future efforts add to the limited body of research that is currently found concerning the positive aspects of the transgender experience. 


\section{References}

Balsam, K. F., Molina, Y., Beadnell, B., Simoni, J., \& Walters, K. (2011). Measuring multiple minority stress: The LGBT people of color microaggressions scale. Cultural Diversity and Ethnic Minority Psychology, 17(2), 163-174. doi: $10.1037 / \mathrm{a} 0023244$

Beemyn, G., \& Rankin, S. (2011). The lives of transgender people. New York, NY: Columbia University Press.

Bilodeau, B. L., \& Renn, K. A. (2005). Analysis of LBGT identity development models and implications for practice. In Sanlo, R. L. (Eds.), Gender identity and sexual orientation: Research, policy, and personal perspectives (New Directions for Student Services, no. 111, pp. 2539). San Francisco: Jossey Bass.

Blumer, M. L. C., Ansara, G., \& Watson, C. M. (2013). Cisgenderism in family therapy: How everyday clinical practices can delegitimize people's gender selfdesignations. Journal of Family Therapy, 24(4), 267-285. doi: $10.1080 / 08975353.2013 .849551$

Bockting, W. O, Benner, A., \& Coleman, E. (2009). Gay and bisexual identity development among female-to-male transsexuals in North America: Emergence of a transgender sexuality. Archives of Sexual Behavior, 38(5), 688-701. doi: $10.1007 / \mathrm{s} 10508-009-9489-3$

Bockting, W. O., Miner, M. H., Swinburne Romine, R. E., Hamilton, A., \& Coleman, E. (2013). Stigma, mental health, and resilience in an online sample of the US transgender population. American Journal of Public Health, 103(5), 943-951 doi:10.2105/AJPH.2013.301241

Bornstein, K. (2013). Gender outlaw: On men, women and the rest of us. Abingdon-on- 
Thames: Routledge.

Braun, V., \& Clarke, V. (2006). Using thematic analysis in psychology. Qualitative Research in Psychology, 3(2), 77-101. doi: 10.1191/1478088706qp063oa

Brown, N. (2010). The sexual relationships of sexual-minority women partnered with trans men: A qualitative study. Archives of Sexual Behavior, 39(2), 561-572. doi: $10.1007 / \mathrm{s} 10508-009-9511-9$

Chang, T. K., \& Chung, Y. B. (2015). Transgender microaggressions: Complexity of the heterogeneity of transgender identities. Journal of LGBT Issues in Counseling, 9(3),217-234. doi: 10.1080/15538605.2015.1068146

Christian, L. M., Dillman, D. A., \& Smyth, J. D. (2008). The effects of mode and format on answers to scalar questions in telephone and web surveys. In Lepkowski, J. M., Tucker, C., Brick, J. M., de Leeuw, E.D., Japec, L., Lavrakas P. J., Link, M. W., \& Sangster, R. L. (Eds.). Advances in telephone survey methodology (pp. 250275). New York City: John Wiley and Sons.

Davis, S. A., \& Meier, C. S. (2014). Effects of testosterone treatment and chest reconstruction surgery on mental health and sexuality in female-to-male transgender people. International Journal of Sexual Health, 26(2), 113-128. doi: $10.1080 / 193117611.2013 .833152$

Edwards-Leeper, L., Leibowitz, S., \& Sangganjanavanich, V. F. (2016). Affirmative practice with transgender and gender nonconforming youth: Expanding the model. Psychology of Sexual Orientation and Gender Diversity, 3(2), 165. doi: $10.1037 /$ sgd0000167

Egan, S. K., \& Perry, D. G. (2001). Gender identity: A multidimensional analysis with implications for psychosocial adjustment. Developmental Psychology, 37(4), 451- 
TRANSGENDER MICROAGGRESSION

463. doi: 10.1037/0012-1649.37.4.451

Felmlee, D. H. (1994). Who's on top? Power in romantic relationships. Sex Roles, 31(56), 275-295. doi: 10.1007/BF01544589

Flanders, C. E., Robinson, M., Legge, M. M., \& Tarasoff, L. A. (2015). Negative identity experiences of bisexual and non-monosexual people: A qualitative report. Gay and Lesbian Mental Health, 20(2), 152-172. doi:

$10.1080 / 19359705.2015 .1108257$

Francis, D. A., \& Reygan, F. 'Let's see if it won't go away by itself.' LGBT microaggressions among teachers in South Africa. Education as Change, 20(3), 180-201. doi: 10.17159/1947-9417/2016/1124

Furman, W., \& Shomaker, L. B. (2008). Patterns of interaction in adolescent romantic relationships: Distinct features and links to other close relationships. Journal of Adolescence, 31(6), 771-788. doi: 10.1016/j.adolescence.2007.10.007

Galupo, M. P., Henise, S. B., \& Davis, K. S. (2014). Transgender microaggressions in the context of friendship: Patterns of experience across friends' sexual orientation and gender identity. Psychology of Sexual Orientation and Gender Diversity, 1(4), 461-470. doi: 10.1037/sgd0000075

Galupo, M. P., Henise, S. B., \& Mercer, N. L. (2016). "The labels don't work very well”: Transgender individuals' conceptualizations of sexual orientation and sexual identity. International Journal of Transgenderism, 17(2), 93-104. doi: $10.1080 / 15532739.2016 .1189373$

Galupo, M. P., Pulice-Farrow, L., \& Ramirez, J. L. (2017). 'Like a constantly flowing river": Gender identity flexibility among non-binary transgender individuals. In Sinnott, J. D. (Ed). Identity flexibility during adulthood: Perspectives in adult 
TRANSGENDER MICROAGGRESSION

development. New York City: Springer.

Galupo, M. P., Sailer, C. A., \& St. John, S. C. S. (2004). Friendships across sexual orientations: Experiences of bisexual women in early adulthood. Journal of Bisexuality, 4(1-2), 37-53. doi: 10.1300/J159v04n01_04

Galupo, M. P., \& Resnick, C. A. (2016). Experiences of LGBT Microaggressions in the Workplace: Implications for Policy. In Kollen, T. (Eds.) Sexual Orientation and Transgender Issues in Organizations (pp. 271-287). New York City: Springer International Publishing.

Gamarel, K. E., Reisner, S. L., Laurenceau, J., Nemoto, T., \& Operario, D. (2014). Gender minority stress, mental health, and relationship quality: A dyadic investigation of transgender women and their cisgender male partners. Journal of Family Psychology, 28(4), 437-447. doi:10.1037/a0037171

Guillén, J. C. (2015) Imposed Hispanicity: How the imposition of racialized and gendered identities in Texas affects Mexican women in romantic relationships with white men. Societies, 5, 778-806. doi: 10.3390/soc5040778

Hill, D. B., \& Willoughby, B. L. B. (2005). Development and validation of the genderism and transphobia scales. Sex Roles, 53(7), 531-544. doi:10.1007/s11199-005-7140$\mathrm{X}$

Hines, S. (2009). Riding the Waves: Feminism, Lesbian and Gay Politics, and the Transgender Debates. In Bhambra, G., \& Demir, I. (Eds.) 1968 in Retrospect (pp. 147-159). London: Palgrave Macmillan UK.

Huynh, V. W. (2012). Ethnic microaggressions and the depressive and somatic symptoms of Latino and Asian American adolescents. Journal of Youth and Adolescence, 41(7), 831-846. doi: 10.1007/s10964-012-9756-9 
James, S. E., Herman, J. L., Rankin, S., Keisling, M., Mottet, L., \& Ana , M. (2016). The Report of the 2015 U.S. Transgender Survey. Washington, DC: National Center for Transgender Equality.

Jones, M. L. (2011). Attitudinal and experiential factors of interethnic romantic relationships among Native American emerging adults. All Graduate Theses and Dissertations, Paper 1100. Retrieved from: http://digitalcommons.usu.edu/etd/1100

Joslin-Roher, E., \& Wheeler, D. P. (2009). Partners in transition: The transition experience of lesbian, bisexual, and queer identified partners of transgender men. Journal of Gay and Lesbian Social Services, 21(1), 30-48. doi: $10.1080 / 10538720802494743$

McCullough, J. R. (2016). Correlates and predictors of anti-transgender prejudice. Doctoral Dissertation. Georgia State University Counseling and Psychological Services Dissertations. Retrieved from: http://scholarworks.gsu.edu/cps_diss/117. Meier, S. C., Sharp, C., Michonski, J., Babcock, J. C., \& Fitzgerald, K. (2013). Romantic relationships of female-to-male trans men: A descriptive study. International Journal of Transgenderism, 14(2), 75-85. doi: 10.1080/15532739.2013.791651

Nadal, K. L. (2011). The Racial and Ethnic Microaggressions Scale (REMS): Construction, reliability, and validity. Journal of Counseling Psychology, 58(4), 470. doi: $10.1037 / \mathrm{a} 0025193$

Nadal, K. L. (2013). That's so gay! Microaggressions and the lesbian, gay, bisexual, and transgender community. Washington DC: American Psychological Association.

Nadal, K. L., Davidoff, K. C., Davis, L. S., \& Wong, Y. (2014). Emotional, behavioral, and cognitive reactions to microaggressions: Transgender perspectives. 
TRANSGENDER MICROAGGRESSION

Psychology of Sexual Orientation and Gender Diversity, 1(1), 72-81. doi:10.1037/sgd0000011

Nadal, K. L., Skolnik, A., \& Wong, Y. (2012). Interpersonal and systemic microaggressions: Psychological impacts on transgender individuals and communities. Journal of LGBT Issues in Counseling, 6(1), 55-82. doi:

$10.1080 / 15538605.2012 .648583$

Nadal, K. L., Whitman, C. N., Davis, L. S., Erazo, T., \& Davidoff, K. C. (2016). Microaggressions toward lesbian, gay, bisexual, transgender, queer, and genderqueer people: A review of the literature. The Journal of Sex Research, 53(4-5), 488-508. doi: 10.1080/00224499.2016.1142495

Nemoto, K. (2009). Racing romance: Love, power, and desire among Asian American/White couples. New Brunswick: Rutgers University Press.

Norwood, K. (2012). Grieving gender: Trans-identities, transition, and ambiguous loss. Communication Monographs, 80(1), 24-45. doi: 10.1080/03637751.2012.739705

Nuttbrock, L. A., Bockting, W. O., Hwang, S., Rosenblum, A., Mason, M., Marci, M., \& Becker, J. (2009). Gender identity affirmation among male-to-female transgender persons: A life course analysis across types of relationships and cultural/lifestyle factors. Sexual and Relationship Therapy, 24(2), 108-125. doi:

$10.1080 / 14681990902926764$

O'Meara, J. D. (1989). Cross-sex friendship: Four basic challenges of an ignored relationship. Sex Roles, 21(7-8), 525-543. doi: 10.1007/BF00289102

Ong, A. D., Burrow, A. L., Fuller-Rowell, T. E., Ja, N. M., \& Sue, D. W. (2013). Racial microaggressions and daily well-being among Asian Americans. Journal of Counseling Psychology, 60(2), 188. doi: 10.1037/a0031736 
Pulice-Farrow, L., Clements, Z., \& Galupo, M. P. (2017). Patterns of transgender microaggressions: The role of gender identity. Manuscript submitted for publication.

Reisner, S. L., Gameral, K. E., Nemoto, T., \& Operario, D. (2014). Dydactic effects of gender minority stressors in substance use behaviors among transgender women and their non-transgender male partners. Psychology of Sexual Orientation and Gender Diversity, 1(1), 63-71. doi: 10.1037/0000013

Reisner, S. L., Poteat, T., Keatley, J., Cabral, M., Mothopeng, T., Dunham, E., ... \& Baral, S. D. (2016). Global health burden and needs of transgender populations: A review. The Lancet, 388(10042), 412-436. doi: 10.1016/S0140-6736(16)00684-X

Riggle, E. D., Rostosky, S. S., \& Reedy, C. S. (2005). Online surveys for BGLT research: Issues and techniques. Journal of Homosexuality, 49(2), 1-21. doi: 10.1300/J082v49n02_01

Smith, L. C., Shin, R. Q., \& Officer, L. M. (2012). Moving counseling forward on LGBT issues: Speaking queerly on discourses and microaggressions. The Counseling Psychologist, 40, 385-408. doi: 10.1177/0011000011403165

Sue, D. W. (2010). Microaggressions in everyday life: Race, gender, and sexual orientation. Hoboken: John Wiley \& Sons.

Sue, D. W., Capodilupo, C. M., Torino, G. C., Bucceri, J. M., Holder, A., Nadal, K. L., \& Esquilin, M. (2007). Racial microaggressions in everyday life: Implications for clinical practice. American Psychologist, 62(4), 271. doi: 10.1037/0003066X.62.4.271

Tate, C. C., Youssef, C. P., \& Bettergarcia, J. N. (2014). Integrating the study of transgender spectrum and cisgender experiences of self-categorization from a 
TRANSGENDER MICROAGGRESSION

personality perspective. Review of General Psychology, 18(4), 302-212. doi:

10.1037/gpr0000019

Tebbe, E., Moradi, B., Ege, E. (2014). Revised and abbreviated forms of the genderism and transphobia scale: Tools for assessing anti-trans* prejudice. Journal of Counseling Psychology, 61(4), 581-592. doi: 10.1037/cou0000043

Testa, R. J., Sciacca, L. M., Wang, F., Hendricks, M. L., Goldblum, P., Bradford, J., \& Bongar, B. (2012). Effects of violence on transgender people. Professional Psychology: Research and Practice, 43(5), 452-459. doi: 10.1037/a0029604

Valdes, F. (2013). Unpacking hetero-patriarchy: Tracing the conflation of sex, gender, and sexual orientation to its origins. Yale Journal of Law and the Humanities, $8(1), 161-211$.

van Anders, S. M. (2015). Beyond sexual orientation: Integrating gender/sex and diverse sexualities via sexual configurations theory. Archives of Sexual Behavior, 44(5), 1177-1213. doi: 10.1007/s10508-015-0490-8

Velez, B. L., Breslow, A. S., Brewster, M. E., Cox, R., Jr., \& Foster, A. B. (2016). Building a pantheoretical model of dehumanization with transgender men: Integrating objectification and minority stress theories. Journal of Counseling Psychology. 63(5), 497-508. doi:10.1037/cou0000136

Whitman, C. N., \& Han, H. (2016). Clinician competencies: Strengths and limitations for work with transgender and gender non-conforming (TGNC) clients. International Journal of Transgenderism, 1-18, Advance online copy. doi: $10.1080 / 15532739.2016 .1249818$

Wright, A. J., \& Wegner, R. T. (2012). Homonegative microaggressions and their impact on LGB individuals: A measure validity study. Journal of LGBT Issues in 
Counseling, 6(1), 34-54. doi: 10.1080/15538605.2012.648578

Ylioja, T., Cochran, G., Woodford, M. R., \& Renn, K. A. (2016). Frequent experience of LGBQ microaggression on campus associated with smoking among sexual minority college students. Nicotine and Tobacco Research, 19(1) Advance online copy. doi: 10.1093/ntr/ntw305 
Table 1. Participant Demographics

\begin{tabular}{|c|c|}
\hline & Total $(\mathrm{N}=363)$ \\
\hline Age Mean (SD) & $23.33(7.65)$ \\
\hline \multicolumn{2}{|l|}{ Gender Raised As (\%) } \\
\hline Female & 12.3 \\
\hline Male & 83.3 \\
\hline No Answer & 4.4 \\
\hline \multicolumn{2}{|l|}{ Sexual Orientation $(\%)$} \\
\hline Pansexual & 25.6 \\
\hline Bisexual & 16.8 \\
\hline Queer & 15.2 \\
\hline Asexual & 11.6 \\
\hline Lesbian & 11.6 \\
\hline Other & 9.4 \\
\hline Gay & 5.5 \\
\hline Fluid & 2.4 \\
\hline Heterosexual & 1.9 \\
\hline \multicolumn{2}{|l|}{ Socio-Economic Status (\%) } \\
\hline Working Class & 30.3 \\
\hline Lower-Middle Class & 20.7 \\
\hline Middle Class & 24.5 \\
\hline Upper-Middle Class & 11.0 \\
\hline Upper Class & 1.7 \\
\hline Don't Know & 7.2 \\
\hline No Answer & 4.6 \\
\hline \multicolumn{2}{|l|}{ Race/Ethnicity (\%) } \\
\hline White/Caucasian & 81.8 \\
\hline Biracial/Multiracial & 7.7 \\
\hline Hispanic/Latino & 3.9 \\
\hline Other & 1.9 \\
\hline Asian/Asian-American & 1.9 \\
\hline Black/African-American & 1.4 \\
\hline American Indian/Alaska Native & 0.8 \\
\hline \multicolumn{2}{|l|}{ Education Level } \\
\hline High School/GED & 23.1 \\
\hline Some College & 41.3 \\
\hline College Degree (BA/ BS/AA) & 22.0 \\
\hline Some Graduate School & 3.5 \\
\hline Graduate Degree & 4.9 \\
\hline
\end{tabular}


Table 2. Thematic Structure

\begin{tabular}{ll}
\hline Main Theme & Subtheme \\
\hline Questioning Identity & Participant's Transgender Identity \\
& Partner's Identity \\
Gendered Expectations & $\begin{array}{l}\text { Gendering Body and Intimacy } \\
\text { Gendered Preferences and Roles }\end{array}$ \\
& \\
Public Negotiation of Transgender Identity & \\
and Relationship & Public vs. Private Behavior \\
& Not Advocating \\
& Disclosure \\
Relationship Dynamics & Grieving \\
& Resistance to Transition \\
& Fighting \\
\hline
\end{tabular}


Appendix A: IRB Approval Forms

\begin{tabular}{ll}
\hline Protocol Id: & 1127 \\
\hline Protocol \#: & 1606001126 \\
\hline Protocol Type: & Student - Masters Thesis \\
\hline Reference ID1: & \\
\hline Protocol Status: & Active - Open to Enrollment \\
\hline Title: & Transgender Microaggressions in the Context of Romantic Relationships \\
\hline Summary/Keywords: & \\
\hline Initial Submission Date: & $06 / 15 / 2016$ \\
\hline Submission Date: & $06 / 15 / 2016$ \\
\hline Approval Date: & $06 / 10 / 2016$ \\
\hline Expiration Date: & $06 / 09 / 2017$ \\
\hline Last Approval Date: & \\
\hline Sequence Number: & 0 \\
\hline FDA IND or IDE \#: & \\
\hline Reference ID2: & \\
\hline Special Review Indicator: & Y \\
\hline Vulnerable Subject Indicator: & \\
\hline Key Study Person Indicator: & \\
\hline Funding Source Indicator: & \\
\hline Correspondent Indicator: & \\
\hline Reference Indicator: & \\
\hline Related Projects Indicator: & \\
\hline
\end{tabular}




\section{Appendix B: SurveyMonkey Online Survey}

\section{Transgender Experiences in Romantic Relationships}

We are a group of researchers from Towson University conducting research on the experience of transgender individuals in romantic relationships. If you choose to participate in this research, you will be asked to complete a brief online survey, which should take approximately 25-30 minutes to complete. During the survey, you will be asked to think about your experiences in romantic relationships and provide examples events that may have happened in these relationships.

Your participation is entirely voluntary. You are not obligated to respond to any questions that you are uncomfortable answering. The survey is designed so that you can indicate "no answer" for individual questions and remain in the study. You may also withdraw from the study at any time without incurring any penalties.

If you decide to participate in this survey, you will not be asked to give information that would allow anyone to identify you. You will not be asked to provide your personal information and your IP address will not be recorded.

There are minimal risks associated with your participation. Risk may be more likely if you are uncomfortable thinking about negative and/or hurtful interactions related to your gender identity. There is the possibility that in some cases thinking about some aspects of romantic relationships could cause distress. You may exit the survey at anytime. Should you feel that you need further assistance, please call the Fenway Health LGBT Helpline at 888.340.4528 (toll free) or the Peer Listening Line 800.399.PEER (toll free).

Even though there are no direct benefits or incentives for participating in this study, we hope that the results of the study will shed light on the experience of transgender individuals in romantic relationships.

Completion of this survey signifies your voluntary consent to participate in this research and that you are at least 18 years of age. You may discontinue your participation in this study at any time by clicking "Exit this survey" in the upper-right-hand corner of the screen.

The Towson University Institutional Review Board has approved this study. If you have any questions regarding this research or its purposes, please contact the faculty advisor for this project, Dr. Paz Galupo, at pgalupo@towson.edu. If you have any questions pertaining to your rights as a participant, please contact Dr. Debi Gartland, Chairperson of the Institutional Review Board for the Protection of Human Participants, at (410)704-2236.

Thank you for your time.

Sincerely,

M. Paz Galupo

Lexi K. Pulice-Farrow 
Towson University

- By agreaing to participate in this study I acknowlodge that:

1. I am at least 18 years of age.

2. I identify as transgender, transewual, gender non-conforming, and / or I have a transgender history.

3. I am currently or formerly in a romantic relationship.

3a. This relationship has been within the last five years.

3b. During at laast part of this relationship, I have identifled as transgender or gander non-conforming and/or had a transgender status or history.

I I ague 

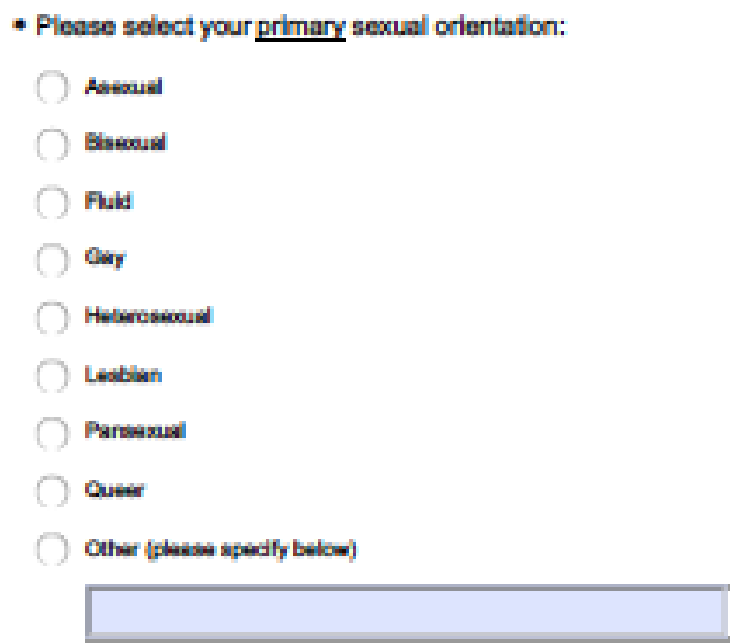

Please list your other sexual identifes, if any.

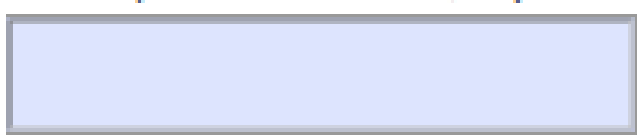




\section{Transgender Experiences in Romantic Relationships}

The next two pages ask questions regarding basic information about yourself (e.g. age, gender). This information is used to understand the diversity of indlividuals who take this survey.

"all questions are optional (solect no answer, or type "na" if you foel uncomfortable answering)

- Socio-Eoonomic Status:

(D) Workng Cless

(2) Lower-Madie Clesa

(1) Midse Clases

(1) Upper-Madle Cleses

(D) Upper Cless

(D) Dom Know

Do Anawer

Ottere (plasese apedily)

(2)

- Race/Ethnicity.

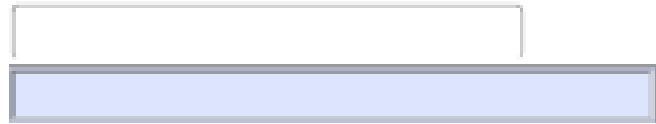

- State of Residence

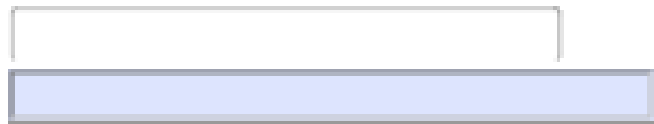




\section{Transgender Experiences in Romantic Relationshlps}

- CurrentAgo

* "What is your highest level of education?

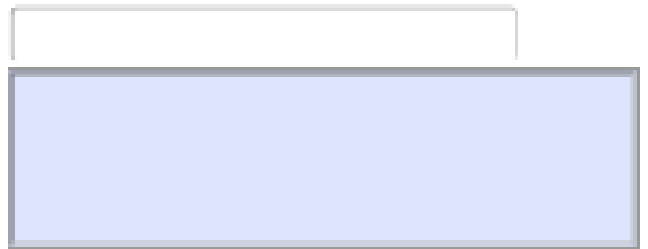

- How did you haar about this study?

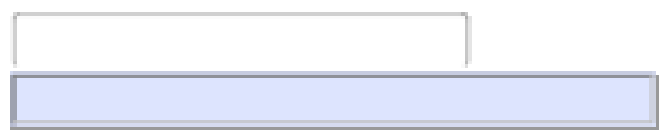




\section{Transgender Experiences in Romantic Relationshlps}

Please think about one romantic partner when answering questions across the study.

The relationship you consider should have taken place within the last flve yoars, and during at least part of this relationship you should have identified as transgender or gonder non-conforming andior had a transgender status or history.

The relationship that I am thinking of:

D was a flomer retatorstip.

is scament retationsitip.

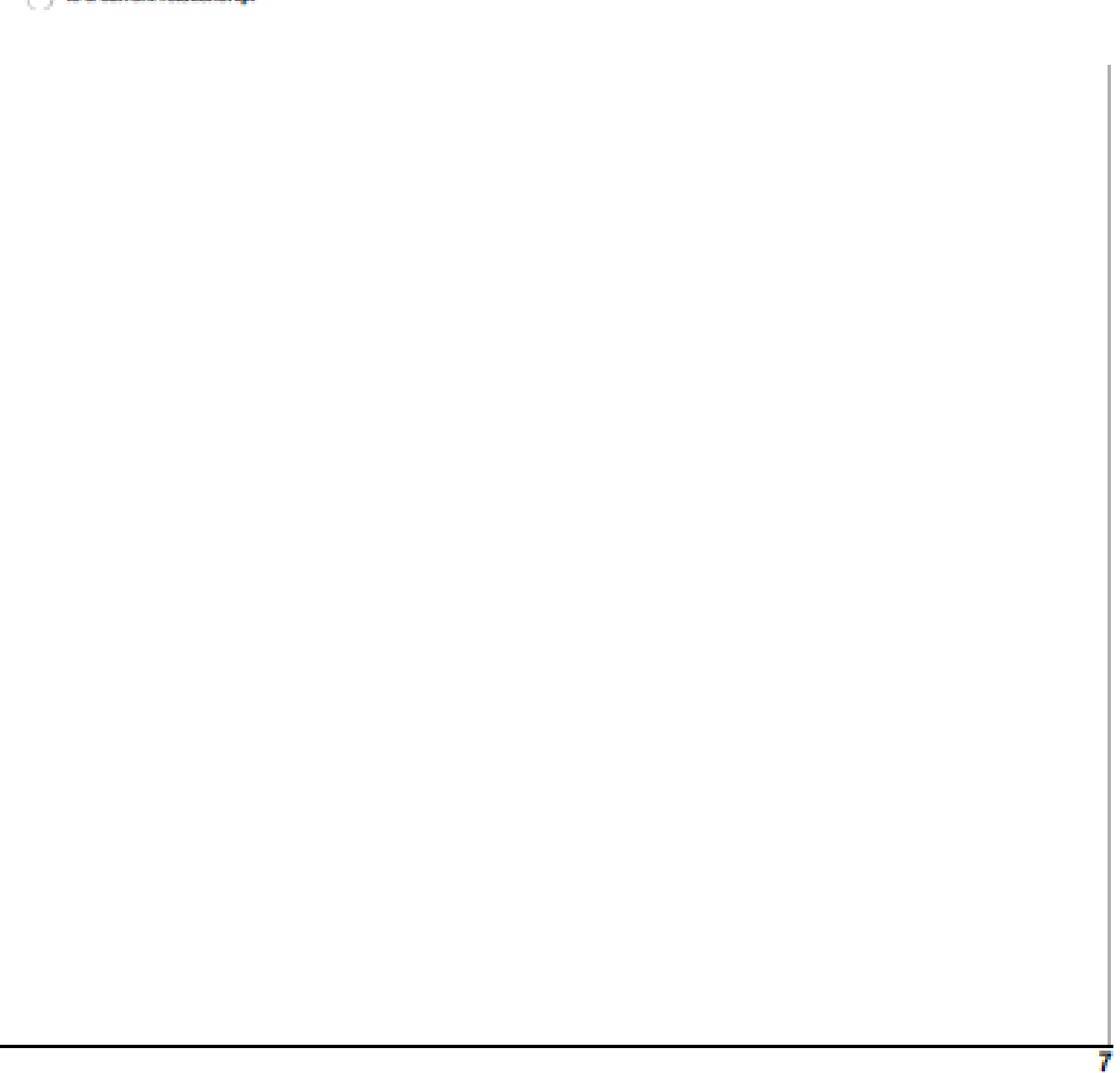




\section{Transgender Experiences in Romantic Relationships}

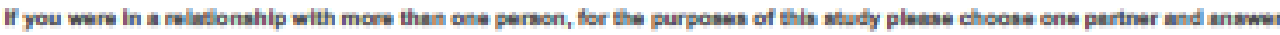
the questiens in reintion te only that individual throughout the durntien of the study.

- My romantic relationship status was. .. (Cheok. Al that Apply)

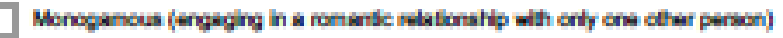

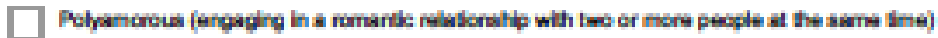

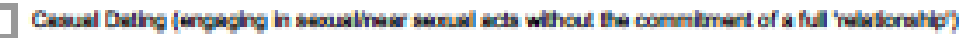

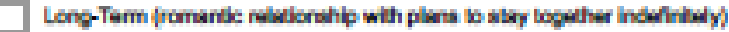

Marriad

Cuhar (plaeswa specify)

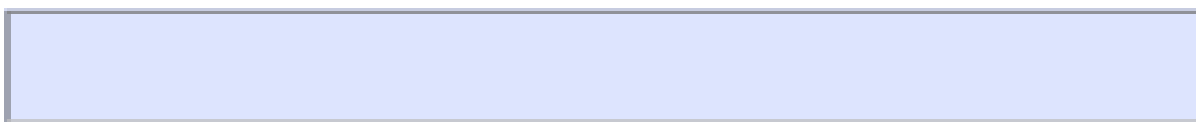

- What was your partner's gender identity?

Ca Woman

(]) Ca Mar

Transfuminira

Trarsmabudine

Oandar Nan-Centorming

(7gunder

Cuher (plasise specify)

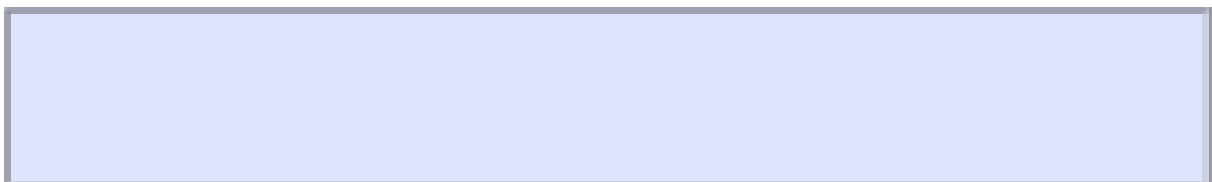

- What gender was your parther raised as?

C Furnala

(T) Mak

No aratest 


\section{Transgender Experiences in Romantic Relationships}

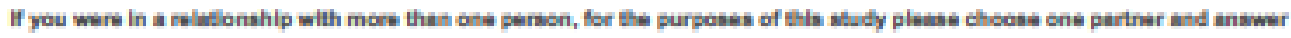
the questiens in reintion to only that individual throughout the duratien of the study.

- My romantic relationship status was. . (Chock Al that Apply)

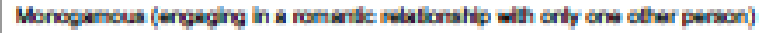

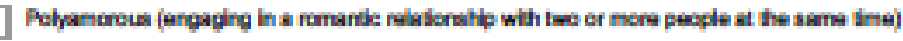

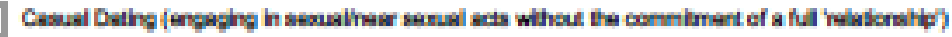

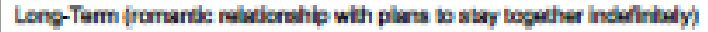

W Marriad

Cutrer (shasea sapedfy)

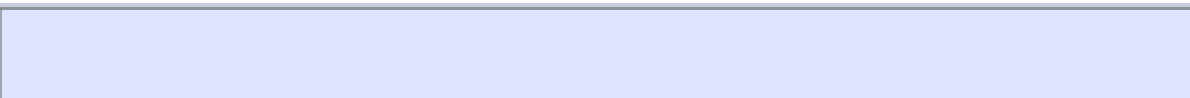

- What was your partner's gender identity?

Ca Woman

O Ca Man

Traesfeminire

Transmabudine

(7) Candar Nan-Centorning

(T) Agunder

(7) Cutar (plassa spadfy)

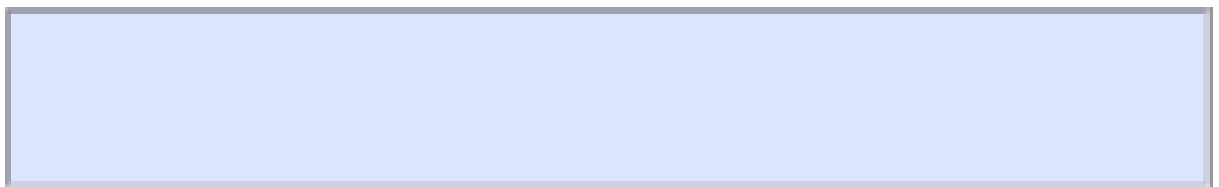

- What gender was your parther raised as?

(]) Fumela

(7) Mak

No andwer 


\section{Transgender Experiences in Romantic Relationshlps}

If you are in a relatienskip with more thas one parsos, for the porposes of this study please checas ose partner and asswer the questiens in reintion te only that individual throughout the duratien of the study.

- My romantic relafonship status is. .. (Chock al that apply)

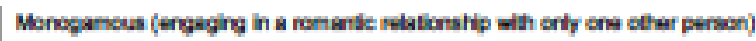

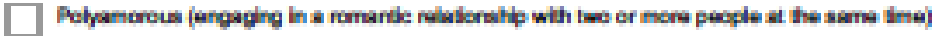

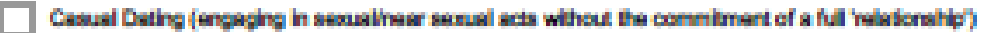

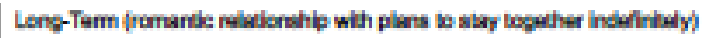

Marriad

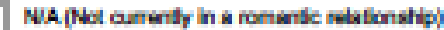

Caher (plassea speady)

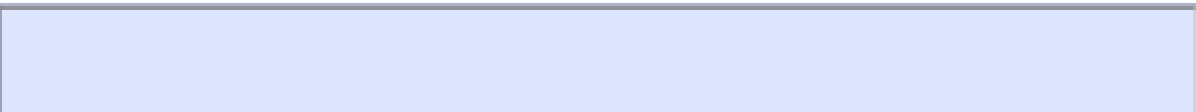

- What is your partner's gender idantity?

( Ca Woman

Ca Man

(1) Trassfuminire

Traramasciline

(D) Gundar Nan-Centurning

Agunder

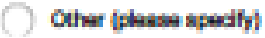

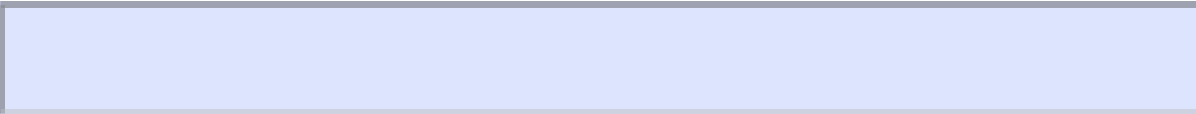

- What gender was your parther raised as?

() Furnete

(D) Male

No andimer 


\section{Transgender Experiences in Romantic Relationshlps}

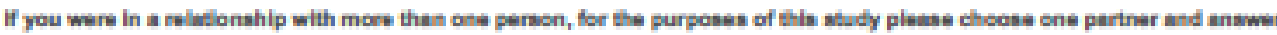
the questiens in reintion to anly that individual throughout the durntien of the study.

- Did you bogin dating your parther. .. (Check all that apply)

belore ary gender trinsibers?

D before sceidly trarsiloning? (charging your name, pronouns, atc)

Defore physicslly transitoring? (boginring HAT, having gendar afliming surgeries, atc)

ator al trinstiben stepa?

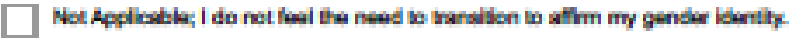

Cuther (phasia spedify)
0-6 mantls
8-12 manth:
) $1-2$ years
(1) $3-5$ years
(D+ years 


\section{Transgender Experiences in Romantic Relationships}

If you are eurrently in a relutienship with mort than one parseb, for the purpesese of this study please eheses ent partner and answer the questions in relation to enty that indlivdual threegheut the durnsion ef the study.

* Did you begin dating your parther. .. (Check all that apply)

betoese ary gender transibons?

$\square$ betoes ascialy trassibening? (charging your name, pronsuns, wle)

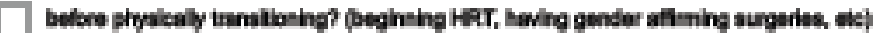

$\square$ ather al trastion stepes?

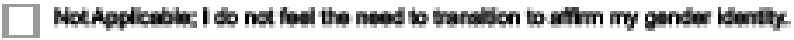

$\square$ Other (abese specly)

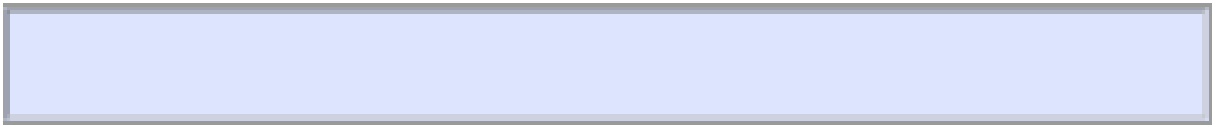

* How long ware you and your partner together?
0.6 mones
6-12 mentha
(1) 1.2 yan
(1)-5 years
2 $6+$ yoars 


\section{Transgender Experiences in Romantic Relationships}

If you are eurrently in a relutienship with more than one parach, for the purpeses of this study plates eheses onte partner and antwwer the quations in relatien to enty that indivdual threugheut the durnton ef the study.

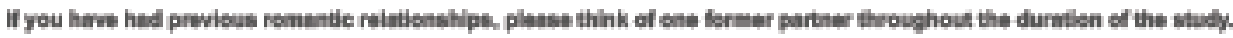

Somotimes, partners may carry out conscious and deliberate violent verbal and nonverbal actions based on gender identity meant to hurt you through name-calling, avoidant behavior, or purposeful discriminatory actions.

- Provide an axample from your romantic partner in which these actions have bean directed toward you basod on your gander identily. Plaase dascribe the experiance in dotal and include both your internal (emotional) reaction as well as any foedbeck or action you mado to the siluation.

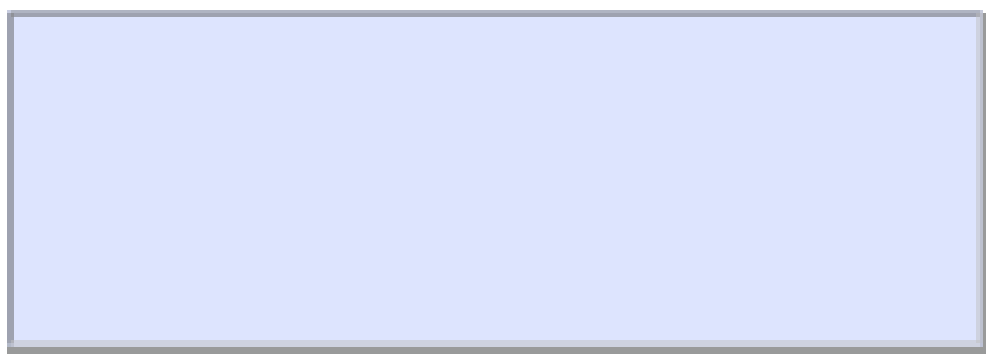

If you choces net is provide an weample, wile NaA and then raspend is the mutple-choles questions below.

* How often do instances such as this oocur in your romantio relationships... 


\section{Transgender Experiences in Romantic Relationships}

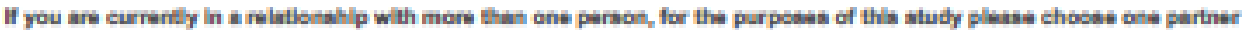

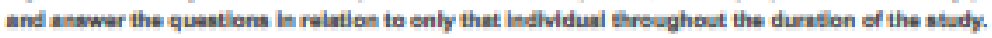

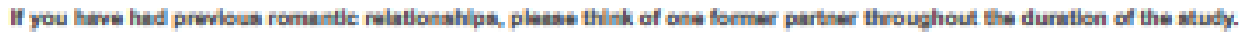

Sometimes, partners may unintentionally carry out behavioral or verbal slights, typically outside of their awareness that convoy rudeness, insensitivity, or demean your gender identity.

- Provide an axample from your romantic partner in which these actons have been directed toward you based on your gander identity. Please describe the experiance in detal and include both your internal (emotional) reaction as well as any feodback or action you made to the sihuation.

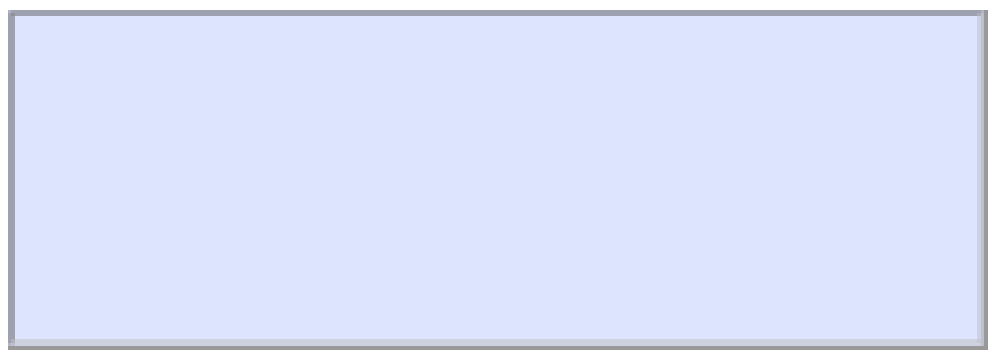

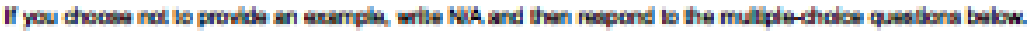

- How often do instances such as this occur in your romantic ralationship...

Nemer Posely Sometimes:

Otan

Alwivgs Ne Answer

Fivquancy

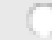




\section{Transgender Experiences in Romantic Relationshlps}

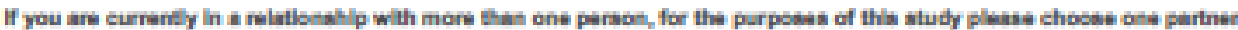

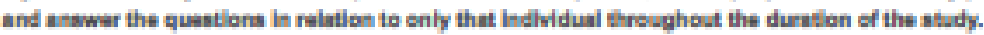

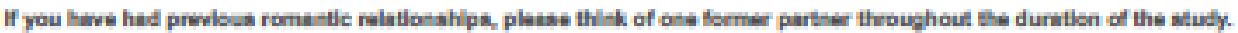

Sometimes, partners may unintentionally carry out verbal comments or behaviors that exclude, negate, or nullify your thoughts, feelings, or experienced reality on the basis of your gender identity.

- Provide an example from your romantic partner in which these actons have been directod troward you basod on your gender identily. Please describe the experlence in detal and include both your internal (emotional) reaction as well as any feodback or action made to the situation.

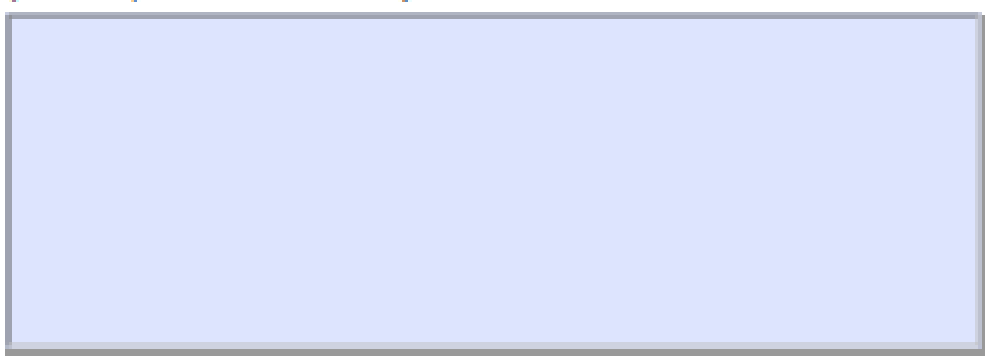

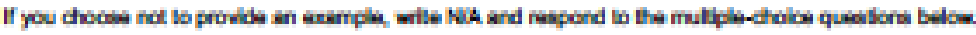

- How often do instances such as this ocour in your romantic relationship..

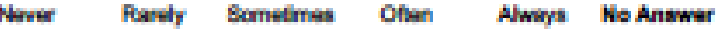

Frequancy

(D) (D)




\section{Transgender Experiences in Romantic Relationshlps}

- Provide an axample from your romantic partner in which a supportive or affirming action has beon directed toward you based on your gender identity. Please describe the exporience in detail and include both your internal (emotional) reaction as well as any feodback or action made to the situstion.

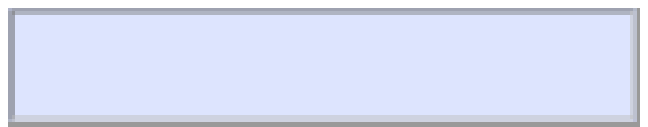

- How frequently do these affliming events occur?

\begin{tabular}{|c|c|c|c|c|c|c|}
\hline & Nherese & Rentuly & Sametimas & Cran & Almays & NacA \\
\hline Frivquancy & & & & & & \\
\hline
\end{tabular}

- Experiences such as these...

\begin{tabular}{|c|c|c|c|c|c|c|c|c|}
\hline & $\begin{array}{l}\text { Suandy } \\
\text { Agree }\end{array}$ & Agrow & $\begin{array}{l}\text { Slighly } \\
\text { Agrese }\end{array}$ & $\begin{array}{l}\text { Silotity } \\
\text { Disugrien }\end{array}$ & Disugnes & $\begin{array}{l}\text { Sungly } \\
\text { Disiggree }\end{array}$ & $\begin{array}{c}\text { Not } \\
\text { Applicsele }\end{array}$ & No \\
\hline poothely inpest my mood for the rast of the dey. & O & O & O & O & O & 3 & O & 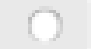 \\
\hline 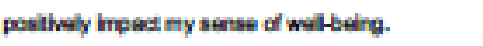 & () & O & O & O & () & ) & () & D \\
\hline une expected coctumariose for me. & O & O & O & O & O & ) & . & ) \\
\hline une plessart for me bo experiance. & O & O & O & O & O & ) & $\lambda$ & . \\
\hline 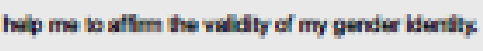 & $\Omega$ & 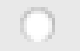 & $\Omega$ & 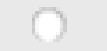 & 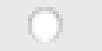 & & & \\
\hline 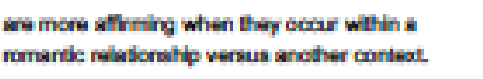 & & & & & & & & \\
\hline 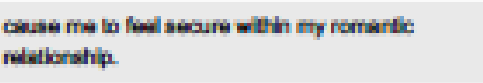 & & & & & & & & \\
\hline Couse me is flowl emotionelly dose is my parner. & $C$ & O & O & J & 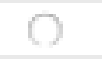 & 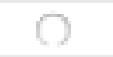 & O & \\
\hline 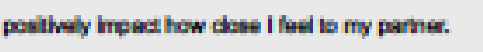 & O & () & O & O & 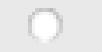 & 7 & O & ) \\
\hline 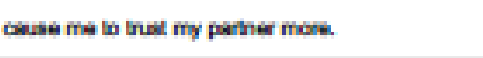 & () & ) & O & O & O & 1) & $\mathrm{C}$ & O \\
\hline 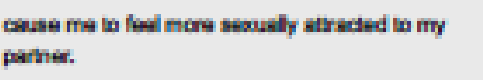 & & & & & 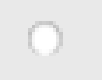 & & () & \\
\hline 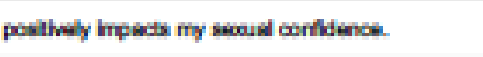 & O & O & O & O & O & () & O & O \\
\hline
\end{tabular}


Transgender Experiences in Romantic Relationships

Thank you for taking this survey. If you have any questions or comments, feel froe to e-mail the principal investigator at pgalupogtowson.edu

Please foel free to let others know about this survey. It can be accessed through:

https:/Wwww.surveymonkey.com/s/transromanticrelationships

We try to create studies that are inclusive and affrming of al identifes. We recognize that some of our questions may not fully capture your individual experiances. In order to improve future studies we walcome feedbeck. If you would like to offer a comment, but wish to remain anonymous, feal free to respond below.

Thark you! 
NAME: Lex Pulice-Farrow

PROGRAM OF STUDY: Clinical Psychology

DEGREE AND DATE TO BE CONFERRED: Master of Arts, 2017

Secondary Education:

Collegiate Institutions Dates Degree Date of Degree Attended

Towson University

August 2015 - May Master of Arts May 2017
2017

Agnes Scott College August 2010 - May Bachelor of Arts May 2014 2014

Major: Psychology

Minor: English Literature

Professional Publications:

- Galupo, M. P., Ramirez, J. L., \& Pulice-Farrow, L. (2017). "Regardless of their gender": Descriptions of sexual identity among bisexual, pansexual, and queer identified individuals. Journal of Bisexuality, 17(1), 108-124. doi:

10.1080/15299716.2016.1228491

- Galupo, M. P., Pulice-Farrow, L., \& Ramirez, J. L. (2017). "Like a constantly flowing river": Gender identity flexibility among non-binary transgender individuals in Sinnott (eds) Identity Flexibility during Adulthood: Perspectives in Adult Development. Springer.

- Jiang, Y., Hughes, J. L., \& Pulice-Farrow, L. (2014). Friends, colleagues, and supervisors on Facebook? Effect of workplace friendship, trust, and gender. Psi Chi Journal of Psychological Research, 19(3), 144-153.

- Pulice-Farrow, L., Hughes, J. L., \& Bohnert, A. (2013). Relationship satisfaction, confidence, and outness in lesbian identified Facebook users. Undergraduate Journal for the Human Sciences 12(1). Retrieved from http://www.kon.org/urc/v12/pulice-farrow.html.

- Bohnert, A., Hughes, J. L., \& Pulice-Farrow, L. (2013). How motives predict usage and liking Facebook. Undergraduate Journal for the Human Sciences 12(1).

Retrieved from http://www.kon.org/urc/v12/bohnert.html. 
Professional Positions Held:

Teaching Assistant for Professor Edward Lomash at Towson University PSYC 457: Psychological Perspectives of Sex and Gender.

Guest Lecturer for Professor Alexandria Luxon at Towson University PSYC: Behavioral Statistics

Teaching Assistant for Dr. M. Paz Galupo at Towson University PSYC 457: Psychological Perspectives of Sex and Gender.

Graduate Facilitator for Towson University's Speaker's Bureau Towson University's Center for Student Diversity, LGBTQ+ Division

Writing Center Graduate Assistant Towson University's Writing Center 
